\title{
Thermal Fill
}

National Cancer Institute

\section{Source}

National Cancer Institute. Thermal Fill. NCI Thesaurus. Code C66862.

An endodontic filling material which is comprised of gutta percha around a plastic core. 